\title{
Incidence and causes of end-stage renal disease among Aboriginal children and young adults
}

\author{
Susan M. Samuel MD MSc, Bethany J. Foster MD MSc, Brenda R. Hemmelgarn PhD MD, \\ Alberto Nettel-Aguirre PhD PStat, Lynden Crowshoe MD, R. Todd Alexander MD PhD, Andrea Soo MSc, \\ Marcello A. Tonelli MD SM; for the Pediatric Renal Outcomes Canada Group
}

Competing interests: Susan Samuel has received grants from the Alberta Children's Hospital

Foundation, the Kidney Foundation of Canada KRESCENT program and the Canadian Child Health Clinician Scientist program. R. Todd Alexander has received a grant from Alberta Innovates Health Solutions. Andrea Soo has received payment from the University of Calgary for data analysis. No other competing interests were declared.

This article has been peer reviewed.

Correspondence to: Susan Samuel, s.samuel @ albertahealthservices.ca

CMAJ 2012. DOI:10.1503 /cmaj.120427

\section{ABSTRACT}

Background: Although Aboriginal adults have a higher risk of end-stage renal disease than non-Aboriginal adults, the incidence and causes of end-stage renal disease among Aboriginal children and young adults are not well described.

Methods: We calculated age- and sex-specific incidences of end-stage renal disease among Aboriginal people less than 22 years of age using data from a national organ failure registry. Incidence rate ratios were used to compare rates between Aboriginal and white Canadians. To contrast causes of end-stage renal disease by ethnicity and age, we calculated the odds of congenital diseases, glomerulonephritis and diabetes for Aboriginal people and compared them with those for white people in the following age strata: 0 to less than 22 years, 22 to less than 40 years, 40 to less than 60 years and older than 60 years.
Results: Incidence rate ratios of end-stage renal disease for Aboriginal children and young adults (age < 22 yr, v. white people) were 1.82 (95\% confidence interval [Cl] 1.40-2.38) for boys and 3.24 (95\% Cl 2.60-4.05) for girls. Compared with white people, congenital diseases were less common among Aboriginal people aged less than 22 years (odds ratio [OR] $0.56,95 \% \mathrm{Cl} 0.36-0.86$ ), and glomerulonephritis was more common (OR $2.18,95 \% \mathrm{Cl} 1.55-3.07)$. An excess of glomerulonephritis, but not diabetes, was seen among Aboriginal people aged 22 to less than 40 years. The converse was true (higher risk of diabetes, lower risk of glomerulonephritis) among Aboriginal people aged 40 years and older.

Interpretation: The incidence of end-stage renal disease is higher among Aboriginal children and young adults than among white children and young adults. This higher incidence may be driven by an increased risk of glomerulonephritis in this population.

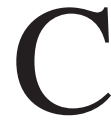
ompared with white Canadians, Aboriginal Canadians have a higher prevalence of end-stage renal disease, ${ }^{1,2}$ which is generally attributed to their increased risk for diabetes. However, there has been limited investigation of the incidence and causes of end-stage renal disease among Aboriginal children and young adults. Because most incident cases of diabetes are identified in middle-aged adults, an excess risk of endstage renal disease in young people would not be expected if the high risk of diabetes is responsible for higher overall rates of end-stage renal disease among Aboriginal people. About $12.3 \%$ of children with end-stage renal disease in Canada are Aboriginal, ${ }^{3}$ but only $6.1 \%$ of Canadian children (age $<19$ yr) are Aboriginal. ${ }^{4,5}$

A few reports suggest that nondiabetic renal disease is common among Aboriginal populations in North America. ${ }^{2,6-8}$ Aboriginal adults in
Saskatchewan are twice as likely as white adults to have end-stage renal disease caused by glomerulonephritis, ${ }^{7,8}$ and an increased rate of mesangial proliferative glomerulonephritis has been reported among Aboriginal people in the United States. ${ }^{69}$ These studies suggest that diabetes may be a comorbid condition rather than the sole cause of kidney failure among some Aboriginal people in whom diabetic nephropathy is diagnosed using clinical features alone.

We estimated incidence rates of end-stage renal disease among Aboriginal children and young adults in Canada and compared them with the rates seen among white children and young adults. In addition, we compared relative odds of congenital renal disease, glomerulonephritis and diabetic nephropathy in Aboriginal people with the relative odds of these conditions in white people. 


\section{Methods}

\section{Data source}

We obtained data from the Canadian Organ Replacement Register, which contains data for all patients with incident end-stage renal disease in Canada. In a recent validation study comparing registry data with detailed clinical data from patient-level medical records, agreement between the two for primary renal disease was reported as $82.8 \%$ for glomerulonephritis and $78.3 \%$ for diabetes. ${ }^{10}$ Lower agreement was noted for ethnicity (58\%); however, discrepancies were frequently due to a specific race reported in the register, but reported as unknown in medical records..$^{10}$ The Conjoint Health Research Ethics Board of the University of Calgary approved the study.

\section{Study population}

Our study involved an incident cohort of all patients less than 22 years of age included in the register during the period Jan. 1, 1992, to Dec. 31, 2007. We calculated age- and sex-specific incidence rates of end-stage renal disease. In addition, we randomly selected a cohort of adult patients with end-stage renal disease (age $\geq 18 \mathrm{yr}$ ), comprising $75 \%$ of adult registrants during the period from Jan. 1, 1990, to Dec. 31, 2000, to calculate odds of glomerulonephritis, diabetes and congenital renal disease by age category in Aboriginal and white patients. The adult dataset comprised two $37.5 \%$ random cohorts that had been previously obtained by one of the investigators (Marcello Tonelli). From this dataset, we excluded patients between the ages of 18 and less than 22 years, because all patients less than 22 years of age were captured in the incident cohort. Therefore, we did not have data on all adult patients with incident end-stage renal disease, and we did not calculate incidence rates for adults 22 years of age and older. Furthermore, we did not include patients from the province of Quebec, because their data were not available for release to investigators at the time of the study. Finally, we excluded recipients of organ transplants other than kidney.

Ethnicity was determined by the health care professional responsible for reporting to the register and was classified as white or Aboriginal (First Nations, Inuit and Métis, including Aboriginal people living on federal reserves). We excluded patients whose ethnicity was not white or Aboriginal.

\section{Statistical analysis}

We described baseline clinical characteristics with either medians and interquartile ranges (IQRs) or proportions. We used a significance level of $\alpha=0.05$ for all statistical tests. We compared characteristics of Aboriginal and white people using $\chi^{2}$ tests for categorical variables.

We calculated age- and sex-specific incidence rates (age categories 0 to $<5 \mathrm{yr}, 5$ to $<10 \mathrm{yr}, 10$ to $<15 \mathrm{yr}, 15$ to $<18 \mathrm{yr}, 18$ to $<22 \mathrm{yr}$ ) of end-stage renal disease, with $95 \%$ confidence intervals (CIs), for Aboriginal people for the duration of the study period. We calculated incidence rate ratios (IRRs) between Aboriginal and white people using unconditional maximum likelihood estimation. We obtained population numbers by age, sex, province and ethnicity from Statistics Canada for census years 1996, 2001 and 2006 to match registrant data, excluding the population of Quebec.

We grouped primary renal disease into 4 categories: congenital anomalies of the kidneys or urinary tract, glomerulonephritis, diabetes and other. We calculated odds ratios (ORs) for each of three causes of end-stage renal disease (congenital anomalies, diabetes, glomerulonephritis) for Aboriginal people compared with white people of the same age (age categories 0 to $<22 \mathrm{yr}$, 22 to $<40 \mathrm{yr}, 40$ to $<60 \mathrm{yr}, \geq 60 \mathrm{yr}$ ). We did not calculate ORs for the group identified as "other" primary renal diseases owing to the heterogeneity of diseases in this group.

Among patients with glomerulonephritis, we modelled the odds of having primary versus secondary glomerulonephritis for Aboriginal people compared with white people, adjusting for age and including an interaction term between age and ethnicity. Primary glomerulonephritis usually involves the kidney only (e.g., immunoglobulin A $[\operatorname{Ig} \mathrm{A}]$ nephropathy and membranoproliferative glomerulonephritis); in secondary glomerulonephritis, kidney involvement is part of a systemic disorder. We calculated proportions for common clinical presentations of glomerulonephritis for Aboriginal people compared with white people of the same age. We also calculated ORs for the most common subtypes of glomerulonephritis (IgA nephropathy and systemic lupus erythematosus) for Aboriginal people compared with white people of the same age. We pooled analyses across sex for all calculations owing to small samples in some categories.

A full list of renal diseases and the classification criteria we used is provided in Appendix 1 (available at www.cmaj.ca/lookup/suppl/doi:10 .1503/cmaj.120427/-/DC1).

\section{Results}

\section{Study population}

A total of 159 Aboriginal and 821 white children and young adults (age $<22 \mathrm{yr}$ ) started renal replacement therapy during the study period 
Table 1: Demographic characteristics of patients with incident end-stage renal disease by ethnicity

\begin{tabular}{|c|c|c|c|}
\hline \multirow[b]{2}{*}{ Characteristic } & \multicolumn{2}{|c|}{ No. of patients (\%) } & \multirow[b]{2}{*}{$p$ value } \\
\hline & Aboriginal & White & \\
\hline $\begin{array}{l}\text { Children and young adults } \\
\text { (Incident) }\end{array}$ & $n=159$ & $n=821$ & \\
\hline Female sex & $97(61.0)$ & $381(46.4)$ & 0.001 \\
\hline \multicolumn{4}{|l|}{$\begin{array}{l}\text { Age at start of renal } \\
\text { replacement therapy, yr }\end{array}$} \\
\hline 0 to $<5$ & $16(10.1)$ & $88(10.7)$ & 0.94 \\
\hline 5 to $<10$ & $16(10.1)$ & $91(11.1)$ & \\
\hline 10 to $<15$ & $37(23.3)$ & $179(21.8)$ & \\
\hline 15 to $<18$ & $35(22.0)$ & $163(19.9)$ & \\
\hline 18 to $<22$ & $55(34.6)$ & $300(36.5)$ & \\
\hline Adults ( $75 \%$ sample) & $n=1113$ & $n=19363$ & \\
\hline Female sex & $591(53.1)$ & $7570(39.1)$ & $<0.001$ \\
\hline \multicolumn{4}{|l|}{$\begin{array}{l}\text { Age at start of renal } \\
\text { replacement therapy, yr }\end{array}$} \\
\hline 22 to $<40$ & $168(15.1)$ & $2381(12.3)$ & $<0.001$ \\
\hline 40 to $<60$ & $545(49.0)$ & $5434(28.1)$ & \\
\hline$\geq 60$ & $400(35.9)$ & $11548(59.6)$ & \\
\hline \multicolumn{4}{|l|}{ Comorbidity } \\
\hline Type 1 diabetest & $296(26.6)$ & $3140(16.2)$ & $<0.001$ \\
\hline Type 2 diabetest & $462(41.5)$ & $3510(18.1)$ & $<0.001$ \\
\hline Myocardial Infarction & $162(14.6)$ & $3889(20.0)$ & $<0.001$ \\
\hline Pulmonary edema & 355 (31.9) & $5528(28.5)$ & 0.02 \\
\hline Stroke or TIA & 105 (9.4) & $2042(10.5)$ & 0.24 \\
\hline Chronic lung disease & 85 (7.6) & $2131(11.0)$ & $<0.001$ \\
\hline Peripheral vascular disease & $224(20.1)$ & $3595(18.6)$ & 0.19 \\
\hline Malignancy & $45(4.0)$ & 1854 (9.6) & $<0.001$ \\
\hline \multicolumn{4}{|c|}{$\begin{array}{l}\text { Note: } \text { TIA }=\text { transient ischemic attack. } \\
{ }^{*} \chi^{2} \text { test. } \\
\text { tIncludes diabetes as a cause of end-stage renal disease and/or as a comorbidity. }\end{array}$} \\
\hline
\end{tabular}

(1992-2007). The age of patients at the start of therapy did not differ significantly between Aboriginal and white patients (Table 1). Compared with white patients, a greater proportion of Aboriginal patients with incident end-stage renal disease were girls or young women (61.0\% v. 46.4\%, $p=0.001)$ (Table 1).

There were 1113 Aboriginal and 19363 white patients in a random sample of $75 \%$ of adult patients with end-stage renal disease who started renal replacement therapy between 1990 and 2000. Compared with white patients, a greater proportion of Aboriginal patients were women $(53.1 \%$ v. $39.1 \%$; $p<0.001)$.

\section{Incidence of end-stage renal disease}

Incidence rates of end-stage renal disease generally increased with age (Table 2). The rate was highest among Aboriginal women aged 18 to less than 22 years (68.25 per million agerelated population). When all age categories were combined, IRRs for Aboriginal people were significantly greater for boys $(1.82,95 \%$ CI 1.40-2.38) and girls (3.24, 95\% CI 2.604.05) (Table 2).

\section{Causes of end-stage renal disease}

Among patients younger than 22 years, a smaller proportion of Aboriginal patients than white patients had end-stage renal disease caused by congenital anomalies $(17.0 \% \mathrm{v}$. 26.9\%; OR 0.56, 95\% CI 0.36-0.86) (Figure 1 and Table 3).

Compared with white patients in the same age group, a greater proportion of Aboriginal people younger than 22 years had end-stage renal disease caused by glomerulonephritis (50.9\% v. 32.3\%; OR 2.18, 95\% CI 1.55-3.07) (Figure 1 and Table 3). Glomerulonephritis was

Table 2: Age- and sex-specific incidence rates and incidence rate ratios of end-stage renal disease among Aboriginal and white children and adolescents

\begin{tabular}{|c|c|c|c|c|c|c|}
\hline \multirow[b]{2}{*}{ Age group, yr } & \multicolumn{2}{|c|}{ Incidence rate* } & \multirow[b]{2}{*}{ IRR $(95 \% \mathrm{CI}) \dagger$} & \multicolumn{2}{|c|}{ Incidence rate* } & \multirow[b]{2}{*}{ IRR $(95 \% \mathrm{CI}) \dagger$} \\
\hline & $\begin{array}{l}\text { Aboriginal boys } \\
\quad(n=62)\end{array}$ & $\begin{array}{l}\text { White boys } \\
\qquad(n=440)\end{array}$ & & $\begin{array}{l}\text { Aboriginal girls } \\
\qquad(n=97)\end{array}$ & $\begin{array}{l}\text { White girls } \\
\quad(n=381)\end{array}$ & \\
\hline 0 to $<5$ & 11.86 & 5.96 & $1.99(0.98-4.05)$ & 9.62 & 4.76 & $2.02(0.90-4.53)$ \\
\hline 5 to $<10$ & 7.65 & 4.70 & $1.63(0.69-3.82)$ & 12.20 & 5.30 & $2.52(1.27-4.99)$ \\
\hline 10 to $<15$ & 13.12 & 8.23 & $1.59(0.83-3.07)$ & 36.97 & 10.26 & $3.60(2.35-5.52)$ \\
\hline 15 to $<18$ & 32.95 & 15.78 & $2.09(1.19-3.66)$ & 51.50 & 11.81 & $4.36(2.67-7.12)$ \\
\hline 18 to $<22$ & 49.05 & 22.01 & $2.23(1.44-3.45)$ & 68.25 & 18.09 & $3.77(2.56-5.55)$ \\
\hline Overall & 19.38 & 10.62 & $1.82(1.40-2.38)$ & 31.45 & 9.70 & $3.24(2.60-4.05)$ \\
\hline
\end{tabular}


also a more common cause of end-stage renal disease among Aboriginal people aged 22 to less than 40 years $(42.9 \%)$ than among white people (34.6\%) in the same age group (OR 1.42 95\% CI 1.03-1.95) (Figure 1 and Table 3). In contrast, fewer Aboriginal patients aged 40 years and older had end-stage renal disease caused by glomerulonephritis $(14.1 \%$ for patients aged 40 to $<60 \mathrm{yr}, 7.8 \%$ for patients aged $\geq 60 \mathrm{yr}$ ) compared with white people in the same age groups $(24.6 \%$ for patients aged 40 to $<60 \mathrm{yr}, 15.4 \%$ for patients aged $\geq 60 \mathrm{yr}$ ) (Figure 1 and Table 3).

Among patients of all ages with end-stage renal disease caused by diabetes $(n=6035)$, $58.9 \%$ of Aboriginal people had type 2 diabetes, whereas a much smaller proportion of white people $(43.7 \%)$ had type 2 diabetes as the cause $(p<0.001)$. The OR for diabetes as the cause of end-stage renal disease was not calculated separately for patients less than 22 years of age, because the sample size was too small to yield an accurate estimate (3 Aboriginal patients, 2 white patients) (Table 3). We saw no significant difference in the proportion of Aboriginal versus white people aged 22 to less than 40 years with end-stage renal disease caused by diabetes. Among patients in this group $(n=804), 40.0 \%$ of Aboriginal people had end-stage renal disease caused by type 2 diabetes, whereas $3.4 \%$ of white people had type 2 diabetes as the cause ( $p$ $<0.001$ ) (data not shown). Among patients 40 years of age and older, diabetes was a more common cause of end-stage renal disease among Aboriginal people (70.5\% for patients aged 40 to $<60 \mathrm{yr}$ and $65.8 \%$ for patients aged $\geq 60 \mathrm{yr}$ ) than among white people (33.9\% for patients aged 40 to $<60 \mathrm{yr}$ and $23.7 \%$ for patients aged $\geq 60 \mathrm{yr}$ ) (Figure 1).

Among patients who had glomerulonephritis $(n=4465), 78.9 \%$ of Aboriginal people and $82.9 \%$ of white people had primary glomerulonephritis (data not shown). There was no difference in odds of primary versus secondary glomerulonephritis in Aboriginal people compared with white people when we adjusted for age (OR 1.10, 95\% CI 0.79-1.50) (data not shown).

Among patients younger than 22 years with glomerulonephritis as a cause of end-stage renal disease, $\operatorname{IgA}$ and mesangial proliferative nephropathies $(28.8 \%$ v. $17.6 \%$; OR 3.05 , 95\% CI 1.72 5.41) were more common among Aboriginal people than among white people. However, we saw no significant difference in the proportion of Aboriginal people versus white people in this age group with systemic lupus erythematosus (11.3\% v. 7.6\%; OR 2.29, 95\% CI 1.03-5.09) (Figure 2 and data not shown).

\section{Interpretation}

Using data from a national registry, we found a significantly higher risk of end-stage renal disease among Aboriginal children and young adults than among their white counterparts. The high risk of this condition in Aboriginal adults is usually attributed to a higher prevalence of diabetes and, thus, diabetic nephropathy. ${ }^{7,11,12}$ However, diabetes is an unlikely cause of end-stage renal disease in children and young adults. ${ }^{3,13-15}$ Our results suggests that the higher incidence of end-stage renal disease among young Aboriginal people is due to their higher risk of glomerulonephritis compared with young white people. Furthermore, congenital anomalies (a major cause of kidney failure in chil-

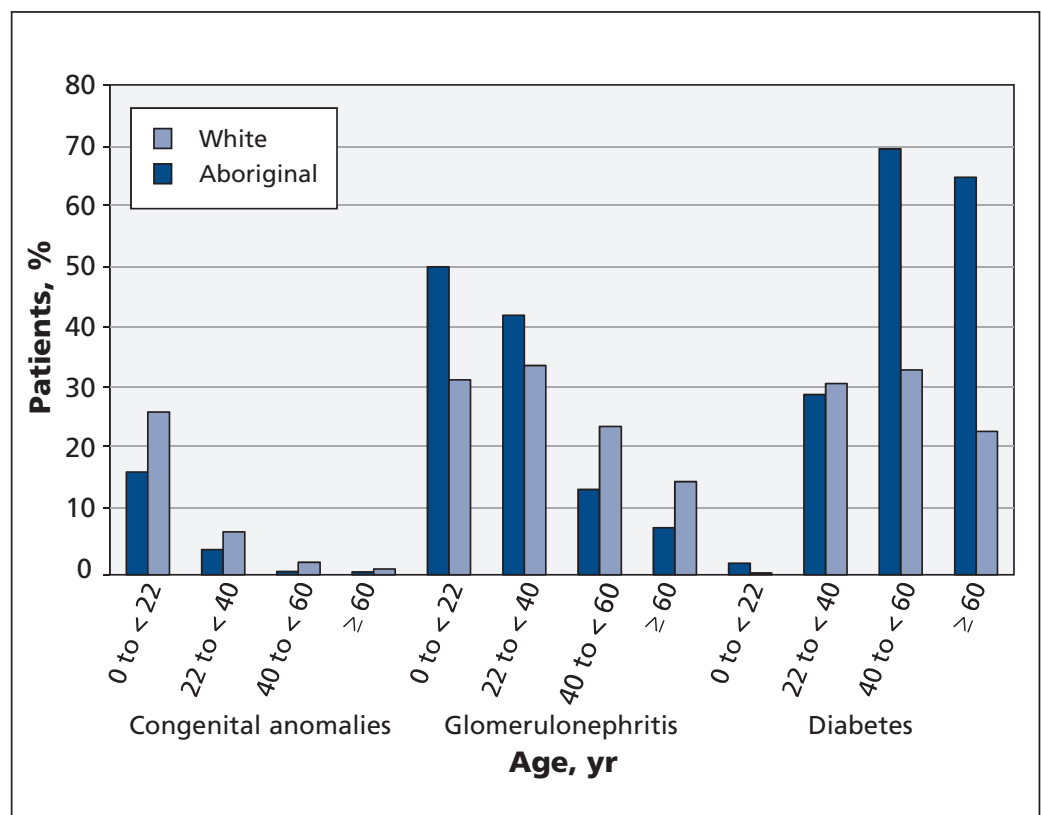

Figure 1: Percentage of patients with end-stage renal disease caused by congenital anomalies of the kidney and urinary tract, glomerulonephritis or diabetes, by age and ethnicity.

Table 3: Odds of congenital anomalies of the kidney and urinary tract, glomerulonephritis and diabetes as the cause of end-stage renal disease in Aboriginal people compared with white people

\begin{tabular}{|lccc|}
\hline & \multicolumn{3}{c|}{ OR $(95 \% \mathrm{Cl})^{*}$} \\
\cline { 2 - 4 } $\begin{array}{l}\text { Age } \\
\text { group, } y r\end{array}$ & $\begin{array}{c}\text { Congenital renal } \\
\text { disease }\end{array}$ & Glomerulonephritis & Diabetes \\
\hline 0 to $<22$ & $0.56(0.36-0.86)$ & $2.18(1.55-3.07)$ & $-\dagger$ \\
\hline 22 to $<40$ & $0.57(0.26-1.24)$ & $1.42(1.03-1.95)$ & $0.91(0.65-1.29)$ \\
\hline 40 to $<60$ & $0.27(0.08-0.85)$ & $0.51(0.39-0.65)$ & $4.66(3.84-5.65)$ \\
$\geq 60$ & $0.53(0.13-2.16)$ & $0.46(0.32-0.67)$ & $6.17(5.00-7.62)$ \\
\hline
\end{tabular}

Note: $\mathrm{Cl}=$ confidence interval, $\mathrm{OR}=$ odds ratio.

${ }^{*} \mathrm{OR}>1.00$ indicates higher odds of disease in Aboriginal people, $\mathrm{OR}<1.00$ indicates higher odds of disease in white people.

tThe sample size was too small to permit an accurate estimate. 
dren) were less common in Aboriginal people than in white people of all ages.

Ours is not the first study to suggest that glomerulonephritis is a more common cause of endstage renal disease in Aboriginal people than in white people. A study involving 247 children in Manitoba found that Aboriginal children were 6 times more likely than white children to present with acquired renal disease (including IgA nephropathy and nephrotic syndrome).${ }^{16}$ In a cohort of Aboriginal children who received renal transplants in British Columbia $(n=24), 58.3 \%$ had glomerulonephritis and $12.5 \%$ had congenital anomalies causing end-stage renal disease. ${ }^{17}$ This observation is striking, because congenital anomalies generally account for 30\%-60\% of pediatric end-stage renal disease in North American and European cohorts. ${ }^{15,18}$

Most previous studies that found higher proportions of Aboriginal children with glomerulonephritis, compared with white children, were single-centre studies and therefore had limited generalizability. Our study used a national sample, thereby improving the generalizability of our results and providing more precise estimates of incidence and odds of the causes of disease. Our large sample allowed us to examine primary and secondary glomerulonephritis separately. Sim-
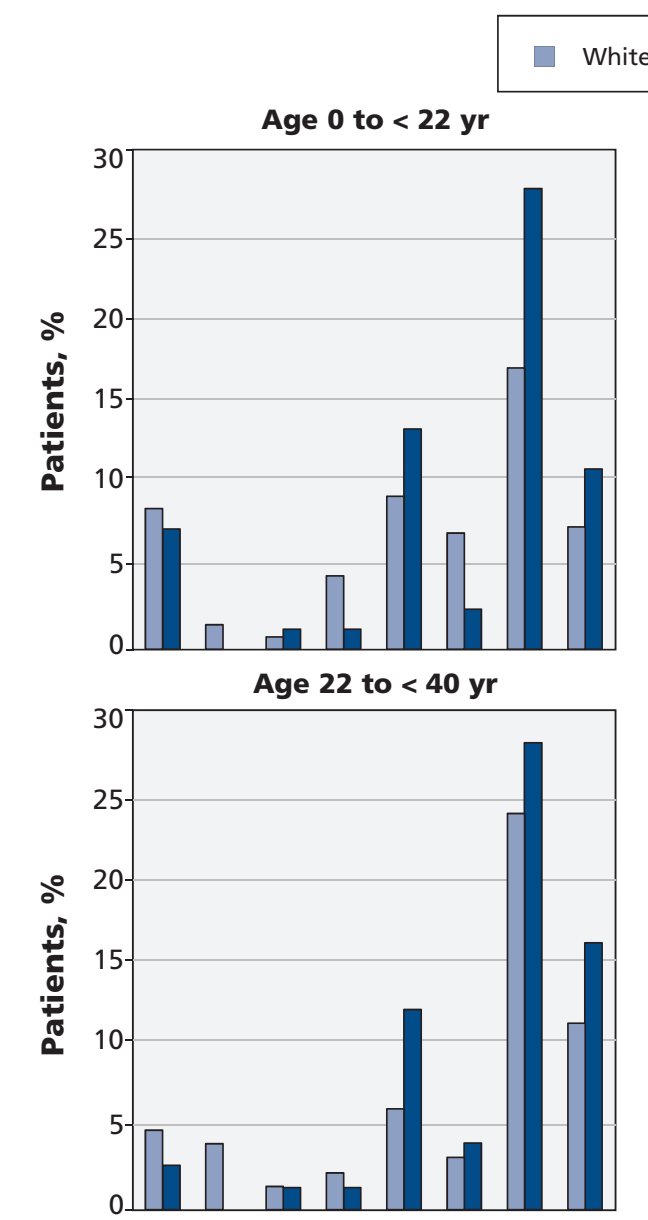

Aboriginal
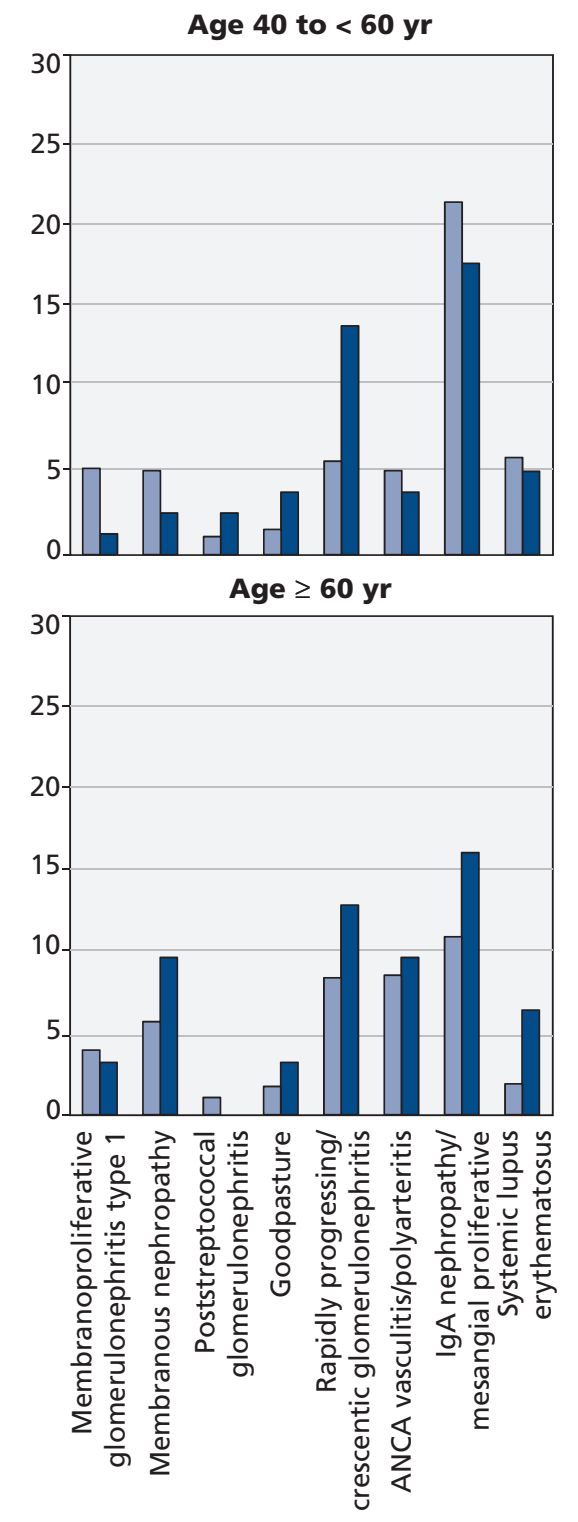

Figure 2: Percentage of patients with various clinical presentations of glomerulonephritis, by age and ethnicity. ANCA = antineutrophil cytoplasmic antibody. 
ilar to previous observations, ${ }^{6,8,9,19}$ we also found a significantly higher proportion of Aboriginal people with both IgA nephropathy and systemic lupus erythematosus compared with white people.

The increased risk of end-stage renal disease (particularly due to glomerulonephritis) that we saw among Aboriginal people raises the question "Why is this happening?" The risk of glomerulonephritis in a given population is determined by complex interactions between genetic predisposition, environmental exposures, socioeconomic conditions and infections. ${ }^{20-22}$ We were unable to determine adjusted risk estimates for infectionrelated glomerulonephritis for Aboriginal children. The same socioeconomic and health disparities that lead to poor health outcomes among Aboriginal adults might also cause increased risk of progression to end-stage renal disease in Aboriginal children and young adults. ${ }^{1,23,28}$

Among patients aged 40 years and older, we saw a lower risk of glomerulonephritis in Aboriginal people than in white people. However, it is possible that the increased risk of glomerulonephritis seen in young Aboriginal people extends to Aboriginal people in this older age group. The frequency of kidney biopsy among adults with diabetes and end-stage renal disease can be less than $20 \%,{ }^{26}$ raising the possibility that diabetes is a comorbid condition rather than the sole cause of kidney failure among some Aboriginal adults with a diagnosis of diabetic nephropathy. Either a high frequency of glomerulonephritis in people with diabetes or coexistence of glomerulonephritis with diabetic glomerulosclerosis has been reported among various cohorts of non-Aboriginal patients. ${ }^{29-32}$ In an observational study involving 567 consecutive renal biopsies in European patients with type 1 or 2 diabetes and chronic kidney disease, about $70 \%$ of patients had diabetic nephropathy and $30 \%$ had other glomerular diseases (e.g., immune complex glomerulonephritis, secondary focal glomerulosclerosis, IgA nephropathy). ${ }^{30}$ In an Australian cohort of patients with diabetes, concomitant nondiabetic renal disease (mostly glomerulonephritis and tubulointerstitial disease) with diabetic glomerulosclerosis was found in 38 of 136 (28\%) consecutive renal biopsies done primarily for proteinuria. ${ }^{29}$

A study involving 90 children (98\% First Nations or Métis) with type 2 diabetes from Manitoba also supports the possibility that diabetes is a comorbid condition. ${ }^{13}$ In that study, $16 \%$ of participants had persistent macroalbuminuria within 8 years of receiving their diagnosis. Of the 10 renal biopsies that were done, 9 showed immune complex disease or glomerulosclerosis; none of them showed classic diabetic nephropathy. Thus, the potential for misdiagnosis and missed curative treatment of coexistent renal disease is particularly important given the high frequency of diabetes and low frequency of glomerulonephritis we saw among Aboriginal adults 40 years of age and older. Furthermore, we suggest that more liberal use of kidney biopsy for definitive diagnosis may be justified in the Aboriginal population.

\section{Limitations}

We relied on voluntary reporting of incident patients to the Canadian Organ Replacement Register. Ethnicity is reported at the discretion of the health care professional reporting to the register; as a result, misclassification may occur and cannot be verified.

Aboriginal ethnicity in the Canadian Organ Replacement Register includes people who selfidentify as First Nations, Inuit or Métis, which are inherently distinct and diverse populations. For this reason, there may be important genetic differences between these groups.

We had no independent verification of primary renal disease or access to biopsy reports. Furthermore, our analysis is limited to patients who have reached end-stage renal disease, and we do not have biopsy results or information about the larger group of people with chronic kidney disease in the population.

\section{Conclusion}

Aboriginal children and young adults are at increased risk of end-stage renal disease compared with white children and young adults. This increased risk is apparently driven by an increased risk of glomerulonephritis that is present at least until the age of 40 years. Further studies are warranted to determine the reasons for the higher risk of glomerulonephritis among young Aboriginal people, and whether an excess risk of biopsyproven glomerulonephritis is also present in Aboriginal adults aged 40 years and older. More liberal use of kidney biopsy should be considered for Aboriginal people with diabetes and proteinuria.

\section{References}

1. Hemmelgarn BR. CSCI Joe Doupe lecture: end-stage renal disease among Aboriginal people. Clin Invest Med 2006;29:383-7.

2. Dyck RF. Mechanisms of renal disease in indigenous populations: influences at work in Canadian indigenous peoples. Nephrology (Carlton) 2001;6:3-7.

3. Samuel SM, Foster BJ, Tonelli MA, et al. Dialysis and transplantation among Aboriginal children with kidney failure. CMAJ 2011;183:E665-72.

4. Canada (Code01) (table). Aboriginal population profile. 2006 Census. Ottawa (ON): Statistics Canada; 2007. Cat. no. 92-594-XWE Available: www12.statcan.ca/census-recensement/2006/dp-pd /prof/92-594/index.cfm?Lang=E (accessed 2012 July 4).

5. Canada (Code01) (table). 2006 community profiles. 2006 Census. Ottawa (ON): Statistics Canada; 2007. Cat. no. 92-591-XWE. Available: www12.statcan.ca/census-recensement/2006/dp-pd /prof/92-591/index.cfm?Lang=E (accessed 2012 July 4).

6. Hoy WE, Smith SM, Hughson MD, et al. Mesangial proliferative glomerulonephritis in southwestern American Indians. Transplant Proc 1989;21:3909-12. 
7. Dyck RF, Tan L. Rates and outcomes of diabetic end-stage renal disease among registered native people in Saskatchewan. CMAJ 1994;150:203-8.

8. Dyck RF, Tan L. Non-diabetic end-stage renal disease among Saskatchewan Aboriginal people. Clin Invest Med 1998;21:33-8.

9. Hughson MD, Megill DM, Smith SM, et al. Mesangiopathic glomerulonephritis in Zuni (New Mexico) Indians. Arch Pathol Lab Med 1989;113:148-57.

10. Moist LM, Richards HA, Miskulin D, et al. A validation study of the Canadian Organ Replacement Register. Clin J Am Soc Nephrol 2011;6:813-8

11. Newman JM, Marfin AA, Eggers PW, et al. End-state renal disease among Native Americans, 1983-86. Am J Public Health 1990;80:318-9.

12. Megill DM, Hoy WE, Woodruff SD. Rates and causes of end-stage renal disease in Navajo Indians, 1971-1985. West J Med 1988;149: 178-82.

13. Sellers EA, Blydt-Hansen TD, Dean HJ, et al. Macroalbuminuria and renal pathology in First Nation youth with type 2 diabetes. Diabetes Care 2009;32:786-90.

14. van Stralen KJ, Tizard EJ, Verrina E, et al. Demographics of paediatric renal replacement therapy in Europe: 2007 annual report of the ESPN/ERA-EDTA registry. Pediatr Nephrol 2010;25:1379-82.

15. Samuel SM, Tonelli MA, Foster BJ, et al. Survival in pediatric dialysis and transplant patients. Clin J Am Soc Nephrol 2011;6:1094-9.

16. Bulloch B, Postl BD, Ogborn MR. Excess prevalence of non diabetic renal disease in native American children in Manitoba. Pediatr Nephrol 1996;10:702-4

17. Matsuda-Abedini M, Al-Alsheikh K, Hurley RM, et al. Outcome of kidney transplantation in Canadian Aboriginal children in the province of British Columbia. Pediatr Transplant 2009;13:856-60.

18. van der Heijden BJ, van Dijk PC, Verrier-Jones K, et al. Renal replacement therapy in children: data from 12 registries in Europe. Pediatr Nephrol 2004;19:213-21.

19. Smith SM, Tung KS. Incidence of IgA-related nephritides in American Indians in New Mexico. Hum Pathol 1985;16:181-4.

20. McGrogan A, Franssen CF, de Vries CS. The incidence of primary glomerulonephritis worldwide: a systematic review of the literature. Nephrol Dial Transplant 2011;26:414-30.

21. Johnson RJ, Hurtado A, Merszei J, et al. Hypothesis: dysregulation of immunologic balance resulting from hygiene and socioeconomic factors may influence the epidemiology and cause of glomerulonephritis worldwide. Am J Kidney Dis 2003;42:575-81.

22. Barsoum RS. Glomerulonephritis in disadvantaged populations. Clin Nephrol 2010;74(Suppl 1):44-50.

23. Bramley D, Hebert P, Jackson R, et al. Indigenous disparities in disease-specific mortality, a cross-country comparison: New Zealand, Australia, Canada, and the United States. N Z Med J 2004; 117:U1215

24. Cass A, Cunningham J, Snelling P, et al. Renal transplantation for indigenous Australians: identifying the barriers to equitable access. Ethn Health 2003;8:111-9.

25. Gao S, Manns BJ, Culleton BF, et al. Prevalence of chronic kidney disease and survival among aboriginal people. J Am Soc Nephrol 2007;18:2953-9.

26. McDonald SP, Russ GR. Current incidence, treatment patterns and outcome of end-stage renal disease among indigenous groups in Australia and New Zealand. Nephrology (Carlton) 2003;8:42-8.

27. Narva A, Stiles S, Karp S, et al. Access of Native Americans to renal transplantation in Arizona and New Mexico. Blood Purif 1996;14:293-304.

28. Yeates KE, Cass A, Sequist TD, et al. Indigenous people in Australia, Canada, New Zealand and the United States are less likely to receive renal transplantation. Kidney Int 2009;76:659-64.

29. Taft JL, Billson VR, Nankervis A, et al. A clinical-histological study of individuals with diabetes mellitus and proteinuria. Diabet Med 1990;7:215-21.

30. Haider DG, Peric S, Friedl A, et al. Kidney biopsy in patients with diabetes mellitus. Clin Nephrol 2011;76:180-5.

31. Soni SS, Gowrishankar S, Kishan AG, et al. Non-diabetic renal disease in type 2 diabetes mellitus. Nephrology (Carlton) 2006; 11:533-7.

32. Robinson LA, Howell DN, Wigfall DR, et al. Appearance of immune complex glomerulonephritis following the onset of type I diabetes mellitus in a child. Am J Kidney Dis 1997;30:713-6.
Affiliations: From the Division of Pediatric Nephrology, Department of Pediatrics (Samuel), the Division of Nephrology, Department of Medicine (Hemmelgarn), the Department of Family Medicine (Crowshoe) and the Department of Community Health Sciences (Soo, Nettel-Aguirre, Hemmelgarn), University of Calgary, Calgary, Alta.; Alberta Children's Hospital (Samuel, Nettel-Aguirre), and the Alberta Children's Hospital Research Institute for Child and Maternal Health (Samuel, Nettel-Aguirre), Calgary, Alta.; the Division of Pediatric Nephrology, Department of Pediatrics and Department of Epidemiology, Biostatistics, and Occupational Health (Foster), McGill University, Montréal, Que.; Montreal Children's Hospital (Foster), Montréal, Que.; the Division of Pediatric Nephrology, Department of Pediatrics (Alexander), and the Division of Nephrology, Department of Medicine (Tonelli), University of Alberta, Edmonton, Alta.; Stollery Children's Hospital (Alexander), Edmonton, Alta.

Contributors: Susan Samuel, Bethany Foster and Marcello Tonelli conceived the idea for the study. Susan Samuel, Brenda Hemmelgarn and Marcello Tonelli obtained the data. Andrea Soo and Alberto Nettel-Aguirre designed the analysis, and Andrea Soo conducted the analysis. Susan Samuel and Marcello Tonelli wrote the manuscript. All of the authors critically reviewed the results and revised the manuscript for important intellectual content. All of the authors approved the final version submitted for publication.

Funding: This work was funded by operating grants from the Alberta Children's Hospital Foundation. Dr. Samuel was supported by an Alberta Heritage Foundation for Medical Research Clinical Fellowship Award during the data acquisition period of this study, and she is currently funded by a joint Canadian Institutes of Health Research (CIHR) Canadian Child Health Clinician Scientist Career Development Award and KRESCENT New Investigator award (Kidney Foundation of Canada). Dr. Foster holds a Fonds de la recherché en santé du Québec Chercheur-Boursier Clinicien award. Dr. Tonelli is supported by a Government of Canada Research Chair in the Optimal Care of People with Chronic Kidney Disease and by a Population Health Scholar Award from Alberta Heritage Foundation for Medical Research. Dr. Hemmelgarn is supported by a Population Health Investigator Award from Alberta Heritage Foundation for Medical Research and by the Roy and Vi Baay Chair in Kidney Research at the University of Calgary. Dr. Alexander is supported by a Clinician Scientist Award from the Canadian Institutes for Health Research, a KRESCENT New Investigator Award and an Alberta Heritage Foundation for Medical Research Clinical Investigator Award. The funding agencies did not participate in analyses or influence the decision to submit the manuscript for publication.

Acknowledgements: The authors thank the director and personnel of the Canadian Organ Replacement Register at the Canadian Institute for Health Information for their assistance in providing the data used in this study. This work was presented in poster form at the World Congress of Nephrology (WCN) 2011 meeting in Vancouver, BC, and as an oral presentation at the WCN satellite meeting for kidney disease in disadvantaged populations in Victoria, BC.

Disclaimer: Parts of this material are based on data and information provided by the Canadian Institute for Health Information. However, the analyses, conclusions, opinions and statements expressed herein are those of the authors and not those of the Canadian Institute for Health Information. 